\title{
Sourcing in the reading process: introduction to the special issue
}

\author{
Lisa Scharrer ${ }^{1} \cdot$ Ladislao Salmerón $^{2}$
}

Published online: 10 August 2016

(C) Springer Science+Business Media Dordrecht 2016

In today's information age, readers seeking to make up their mind or extend their knowledge about a particular issue are confronted with a huge wealth of information. In addition to traditional print media, the growth of the Internet has granted access to a multitude of information on virtually any topic. As a result, the individual who reads up on an issue can usually draw on relevant text information from various sources (Alexander \& the Disciplined Reading and Learning Research Laboratory, 2012; Goldman \& Scardamalia, 2013). However, the host of available knowledge sources poses specific challenges that readers need to overcome in order to successfully use the provided information.

Different sources may address a given topic from different perspectives; they may contradict, complement, or confirm each other. For readers to obtain a complete understanding of the topic of interest, they need to integrate these multiple accounts (Bråten, Britt, Strømsø, \& Rouet, 2011; Perfetti, Rouet, \& Britt, 1999; Stadtler \& Bromme, 2014). In addition, sources may vary in terms of credibility. This issue is especially pressing in online reading contexts, where publication is not subject to any editorial control, and everybody can publish regardless of their level of competence or vested interests. Readers therefore need to carefully evaluate whom they trust and whose information they accept as valid (Brand-Gruwel \& Stadtler, 2011; Britt \& Aglinskas, 2002).

Lisa Scharrer

lisa.scharrer@wwu.de

1 Department of Psychology, University of Muenster, Fliednerstrasse 21, 48149 Muenster, Germany

2 ERI Lectura and Department of Developmental and Educational Psychology, University of Valencia, Valencia, Spain 
In light of these challenges, it is not sufficient for readers to only process the provided text content. Beyond that, it is vitally important that they also gain information about the source. The source of a text can refer to the author, the publisher, the document type, the publication date, or any feature that defines by whom, in which context, and for which purpose the text content was created (see Bråten, Strømsø, \& Britt, 2009; Britt \& Aglinskas, 2002; Britt \& Rouet, 2012).

The present special issue brings together research on individual as well as textual factors that affect readers' attention to and consideration of source information. In what follows, we will contextualize the research from this special issue by briefly reviewing the recent rise in research on "sourcing". As a complete review of the literature is beyond the scope of this introduction, we refer interested readers to recent reviews for more detail (e.g., Bråten, Stadtler, \& Salmerón, 2016). We will finally provide an overview over the contributions to this issue.

\section{Importance of sourcing during reading}

In reading and education research as well as in information science, scholars refer to the processing of information about a source as sourcing. The term sourcing is broadly defined in the literature; it is used as an umbrella concept encompassing various mental activities focused on source information. These include attending to and memorizing source information, evaluating source information, and using source information to evaluate content (e.g., Britt \& Aglinskas, 2002; Rouet, 2006; Wineburg, 1991).

Sourcing activities can serve different functions to meet the outlined challenges of modern reading situations by supporting information evaluation, decisionmaking, and comprehension of multiple views. For the purpose of information evaluation, readers may be able to deduce the believability of encountered content from source information, such as indicators of the author's competence and motivation, the prestige of the publication outlet, or the recency of the publication (Britt \& Aglinskas, 2002; Wineburg, 1991). Such an assessment of information validity by means of source evaluation is particularly important if readers' prior topic knowledge is insufficient to evaluate the contents directly (Bromme, Kienhues, \& Porsch, 2010; Bromme \& Goldman 2014; Stadtler \& Bromme, 2014). Empirical evidence confirms that readers use source information for the purpose of validity evaluation at least sometimes (e.g., Bråten, Strøms $\varnothing$, \& Salmerón, 2011; Britt, Perfetti, Sandak, \& Rouet, 1999; Bromme, Scharrer, Stadtler, Hömberg, \& Torspecken, 2015; Kobayashi, 2014; Thomm, Hentschke, \& Bromme, 2015). For example, Kobayashi (2014) had undergraduates read two conflicting accounts about a scientific topic from sources described as varying in professionalism and thereby in credibility. After reading, the students were more inclined to express agreement with the credible source and disagreement with the less credible source in a written communication task. However, it should be noted that readers' engagement in sourcing for the purpose of evaluation appears to depend on a variety of conductive conditions, such as receiving explicit instruction or prompts (Gerjets, Kammerer, \& Werner, 2011; Stadtler \& Bromme, 2007; Stadtler, Paul, 
Globoschütz, \& Bromme, 2015), subscribing to the belief that knowledge should be evaluated through logic and rules (Strøms $\varnothing$, Bråten, \& Britt, 2011), or possessing disciplinary expertise (Rouet, Favart, Britt, \& Perfetti, 1997; Wineburg, 1991) or relevant prior knowledge (Bråten et al., 2011b).

In the course of evaluation, sourcing can guide readers' decision-making during information inquiry on the Internet. Sourcing becomes essential to filter relevant and trustworthy webpages. Readers tend to filter information in two different ways, either by using quick and frugal source heuristics (e.g., go straight to the first link on a search engine results page) or more elaborate sourcing activities (e.g., evaluate the webpages' URLs to decide which one to access) (Metzger \& Flanagin, 2013). While using source heuristics may to some extent be efficient when searching for noncontroversial information, it certainly increases the chance of accessing unreliable information if a controversial topic is being searched, because webpages listed on top of search engine result pages can be one-sided or commercially biased (Lewandowski, 2011). The use of elaborated sourcing to select webpages is related to design factors, such as avoiding the list format presentation of the results (Kammerer \& Gerjets, 2012), as well as individual factors, such as prior knowledge on the topic searched (Salmerón, Kammerer, \& García-Carrión, 2013).

Sourcing is also relevant when readers access webpages to inform their future actions, for example buying a product or following a daily health recommendation. In such scenarios, sourcing may play a role in whether or not readers adhere to the recommended action. Research reveals that as the author's perceived expertise increases, so do readers' intentions to buy the recommended product (Casaló, Flavián, \& Guinalíu, 2011) or to recommend the advice to a fictitious friend (Salmerón, Macedo-Rouet, \& Rouet, 2016). Other source credibility cues, such as the inclusion of personal experiences as evidence to support the recommendations, become salient in scenarios related to personal risk, for example deciding about vaccinations. Accordingly, Betsch, Ulshöfer, Renkewitz, and Betsch (2011) found that after reading a forum reporting on negative personal experiences with vaccines, readers' intentions towards vaccination decreased as a function of the number of experiences reported.

In addition to supporting content evaluation and decision-making, sourcing may facilitate comprehension of single as well as multiple accounts (Brand-Gruwel \& Stadtler, 2011; Goldman \& Scardamalia, 2013). In the case of single-document comprehension, readers are well advised to evaluate the credibility of the document source before accepting its content as valid knowledge. In addition, knowledge about the source (e.g., the author's ideology or historical background) may be paramount to interpreting the meaning of single text documents (see Strøms $\varnothing$, Bråten, \& Britt, 2010). Accordingly, findings by Sparks and Rapp (2011) suggest that when readers are given instructions and reminders to consider source information, source credibility influences single-text comprehension.

The evaluation of content by means of sourcing can similarly facilitate multipledocument comprehension by helping readers determine what information is worth including in their mental representation. In addition, attending to source information allows readers to make sense of potentially conflicting perspectives, and linking content information to their respective sources enables readers to represent conflicts 
and points of agreement in a differentiated manner (Barzilai \& Eshet-Alkalai, 2015; Bråten et al., 2011a; Bråten, Ferguson, Strøms $\varnothing$, \& Anmarkrud, 2014). Hence, sourcing is required to form an integrated and complete mental representation of the topic that accounts for the multitude of perspectives (Rouet, 2006; Perfetti et al., 1999). Previous research has confirmed a positive relationship between sourcing activities and multiple-document comprehension (e.g., Bråten et al., 2009; Strøms et al., 2010; Wiley et al., 2009). For instance, in a study by Strøms $\varnothing$ et al. (2010), students' memory for source information after reading a set of documents about climate change predicted their deep text comprehension, assessed through a sentence-verification task. In sum, while sourcing facilitates both single- and multiple-document comprehension, reading multiple documents requires intertextual integration in addition to careful evaluation, which brings the importance of sourcing to the fore.

In spite of the central role sourcing plays in the reading process, many studies show that readers often do not engage in sourcing activities spontaneously. In many situations, adolescent and adult readers fail to notice source information, and when they do notice sources, they often do not consider them for evaluating the content (e.g., Barzilai, Tzadok, \& Eshet-Alkalai, 2015; Britt \& Aglinskas, 2002; Eysenbach \& Köhler, 2002; Kobayashi, 2014; Stadtler \& Bromme, 2007, 2008; Steffens, Britt, Braasch, Strøms $\varnothing$, \& Bråten, 2014; Strøms $\varnothing$, Bråten, Britt, \& Ferguson, 2013; Wineburg, 1991; Wiley et al., 2009). These findings raise the question of why readers frequently omit sourcing activities. What are the conditions that make sourcing more or less likely to occur? Although researchers have begun to address this question empirically, our knowledge about factors that affect readers' sourcing activities is still scarce.

\section{This issue}

This issue aims to further our knowledge of conditions under which readers are more or less inclined to engage in sourcing. The contributions focus on different factors that affect sourcing behavior. Knowledge about these factors may help educators derive interventions that facilitate sourcing and thereby support readers in reading comprehension and evaluation processes. The contributions are organized according to the types of factors they investigate. The first portion of articles focuses on textual influences on sourcing, followed by papers that assess the influence of individual factors. In the remainder of this introduction, we briefly summarize the contributions in the order in which they appear in the issue.

Rouet, Le Bigot, de Pereyra, and Britt (2016) investigate how textual discrepancy affects the extent to which readers engage in sourcing. In three experiments, the authors test the assumption that readers' attention to source information increases when encountering discrepant stories, since attributing different accounts to different sources helps recipients make sense of the contradiction. Hence, attention to and memory for source information should be increased when encountering discrepant compared to consistent text information. Participants from two countries read brief stories about everyday events in which different sources give either 
opposing or consistent accounts. In line with Rouet et al.'s (2016) expectations, readers mention more sources in their summary of discrepant than of consistent stories (Experiments 1 and 2) and better remember sources from discrepant stories (Experiment 3).

Braasch, McCabe, and Daniel (2016) examine how the textual factor message congruency affects readers' source memory in multiple-document reading scenarios. The authors assume that statements by different sources that are semantically congruent stimulate readers to engage more in semantic content integration than statements that are semantically distinct. Based on the Documents Model Framework (Britt et al., 1999; Britt \& Rouet, 2012; Perfetti et al., 1999), it is hypothesized that the increased effort invested in forming an integrated mental model disrupts the creation of an intertext model linking the contents to their respective sources. This in turn should lead to poorer source memory among readers of semantically congruent compared to semantically distinct statements. In three experiments, Braasch et al. (2016) present readers with statements from different sources that vary in semantic congruency and afterwards assess participants' source memory. The findings confirm that source memory is impaired after reading semantically congruent compared to distinct statements (Experiment 1). This effect holds if readers receive a pre-reading-warning (Experiment 2) and if the sources' messages consist of whole arguments rather than single sentences (Experiment 3 ).

Bråten, Strøms $\varnothing$, and Andreassen (2016) report a study that simultaneously assesses the influence of two textual features, source salience and emphasis on risk, on sourcing when reading single documents about two scientific issues. The authors hypothesize that high salience of document sources (primary sources) and sources cited within the text document (embedded sources) increases readers' memory for source information and their consideration of sources to justify a topic-related behavioral decision. In addition, textual emphasis on risk associated with the scientific topic should render the topic more relevant to readers and consequently facilitate sourcing efforts. Participants are tasked with reading single text documents in which source salience is varied and which either do or do not imply a topicrelated health risk. After reading, memory for source information is assessed and participants are asked to justify a behavioral decision. The findings show that while source salience and emphasis on risk slightly affect sourcing activities, readers overall appear to pay very limited attention to source information and hardly refer to sources when justifying their topic-related decisions.

The contribution by Thomm and Bromme (2016) focuses on the interplay of the textual factor "source credibility" and the individual factor "attribution of intertextual conflict". Specifically, the authors study how source credibility influences readers' judgments about a scientific controversy, and if this effect is mediated by how readers interpret the conflict. The study presents two conflicting views on the topic of climate change. While one of the authors is an expert with no vested interests (university professor), the second author is presented under three conditions: a junior researcher (expertise condition), a researcher in industry (benevolence condition), or a different university professor (control condition). After reading the two documents, participants complete the Explaining Conflicting Science Claims Questionnaire (Thomm et al., 2015), aimed at identifying readers' 
explanations for a controversy, rate the sources' credibility, judge their personal agreement with each of the statements of the controversy, and complete a source memory test. Memory for sources is high in conditions where sources differ in their credibility, while it is rather low for the control condition, which uses sources with similar levels of credibility. Credibility for sources differs only in the benevolence condition (lower credibility for the researcher in industry than for a full professor), but not in the other conditions in which university professors are the authors. In addition, source characteristics do not impact participants' judgment of each of the claims of the controversy. Finally, participants' explanations for the controversy reflect the differences between the credibility of the sources: when a full professor confronts a researcher in industry, more explanations based on the authors' motivation are used; when a full professor confronts a junior researcher, more explanations based on the authors' competence are given. In the expertise condition, such explanations mediate the relation between source characteristics and perceived credibility of the sources.

The subsequent two contributions assess the influence of individual factors on sourcing. Salmerón, Gómez, and Fajardo (2016) investigate to what extent sources are considered for information evaluation among students with intellectual disabilities (ID) who read recommendations from social question-and-answer forums on the Internet. Given that ID has been associated with increased levels of credulity (Greenspan, Loughlin, \& Black, 2001), Salmerón and colleagues expect students with ID to consider source information to a lesser extent when evaluating forum recommendations than students without ID. Similarly, students with ID should refer less to expert sources when explaining their judgment. To test these assumptions, students with ID and two control groups without ID, matched in chronological age and verbal mental age, respectively, are asked to read recommendations from social question and answer forums about different everyday topics. The recommendations are authored either by self-identified experts or by sources under pseudonym whose expertise is unclear. In addition, the claim of the recommendation is supported either by reference to a documentary source or by personal experience. After reading, participants indicate whether and why they would advise a fictitious user to follow the recommendation. The results show that while control group students recommend advice by expert sources more than advice by sources under pseudonym, students with ID make no such distinction. They generally tend to affirm the forum recommendations and scarcely refer to expert sources when providing reasons for their advice.

Von der Mühlen, Richter, Schmid, Schmidt, and Berthold (2016) investigate the differences in sourcing between scientists and undergraduate students in the field of psychology. This comparison is framed in the development of a computerized test to evaluate the knowledge and use of sourcing-related strategies. Von der Mühlen et al. (2016) find that scientists perform better in both heuristic (quick credibility evaluations) and systematic (plausibility assessments of sentences with argumentation errors) sourcing strategies. Scientists are also better at identifying the genre of documents typical in an undergraduate educational setting. Performances on the three types of tasks are correlated, which suggests that knowledge of genres and use of sourcing strategies develops hand in hand as part of the discipline expertise 
(Rouet et al., 1997). In addition, von der Mühlen et al. (2016) use think-aloud protocols to understand the processing differences between scientists and students. The use of source-related criteria, such as document author or genre, as measured by participants' think-aloud protocols, fully mediates the difference in performance between scientists and students in the quick credibility evaluations. The use of other strategies focusing more on the content, such as evaluation of the line of argumentation or of the theoretical foundations, does not explain the differences. All together, these patterns indicate that scientists are flexible in using heuristic and systematic evaluations, and that source information is particularly relevant when performing quick assessments of the credibility of documents.

The final empirical contribution of the special issue presents an intervention measure designed to improve sourcing activities among readers. Stadtler, Scharrer, Macedo-Rouet, Rouet, and Bromme (2016) develop and test a brief instructional program aimed at fostering vocational students' identification and evaluation of source information in science controversies. This is a population of struggling readers, which makes this intervention particularly challenging. The instructional program emphasizes the importance of understanding the division of cognitive labor in society to resolve science controversies. The program combines different instructional approaches, including teacher-based instruction, group and individual work, complemented by teachers' feedback. Tasks are sequenced to gradually grant further responsibility to students. Participants are tested in a pre-post design, and a waiting-list group is used as the control group. In the pre- and post-tests, participants read a set of documents presenting a science controversy. Participants judge the validity of the two claims for each controversy, write a justification for their judgments, and recall the sources of the documents. Results show that participants in the instructional group, but not those in the control group, engage more in sourcing activities in the post- than in the pre-test, as indicated by a higher agreement with expert positions as well as a higher number of written arguments supported by reference to sources. Memory for sources does not change as a function of group, but it is higher when the two sources are experts in the controversial topic than when only one author is an expert. In sum, Stadtler et al. (2016) demonstrate that sourcing skills can be taught with well-designed programs, even to adolescent struggling readers.

The special issue closes with a commentary by Chinn and Rinehart (2016) in which both authors critically reflect on the main issues addressed by the individual empirical contributions. Chinn and Rinehart (2016) furthermore suggest fruitful avenues for future research in the field. In particular, they argue that source credibility is not merely determined by specific source attributes, but is rather a function of the reliability of processes which sources apply to produce knowledge claims. Chinn and Rinehart call for a consideration of the reliability of processes in future research on sourcing to better understand and facilitate accurate source evaluation.

Acknowledgments We would like to thank Reading and Writing, in particular the Editor-in Chief R. M. Joshi, for their support of this special issue. In addition, we thank all reviewers for volunteering their valuable time and expertise to provide helpful feedback and suggestions on the individual contributions. 
We furthermore thank Celeste Brennecka for language editing this introduction. The present special issue was stimulated by a DFG-funded workshop on "Situating the Comprehension of Multiple Documents in General Models of Reading Competence", held in October 2013 at the University of Münster, Germany (organizers Marc Stadtler and Rainer Bromme). The workshop was realized in the context of the Special Priority Program on Science and the Public, www.scienceandthepublic.de.

\section{References}

Alexander, P. A., \& the Disciplined Reading and Learning Research Laboratory. (2012). Reading into the future: Competence for the 21st century. Educational Psychologist, 47, 1-22. doi:10.1080/ 00461520.2012 .722511$.

Barzilai, S., \& Eshet-Alkalai, Y. (2015). The role of epistemic perspectives in comprehension of multiple author viewpoints. Learning and Instruction, 36, 86-103. doi:10.1016/j.learninstruc.2014.12.003.

Barzilai, S., Tzadok, E., \& Eshet-Alkalai, Y. (2015). Sourcing while reading divergent expert accounts: Pathways from views of knowing to written argumentation. Instructional Science, 43, 737-766. doi:10.1007/s11251-015-9359-4.

Betsch, C., Ulshöfer, C., Renkewitz, F., \& Betsch, T. (2011). The influence of narrative vs. statistic information on perceiving vaccination risks. Medical Decision Making, 31, 742-753. doi:10.1177/ 0272989X11400419.

Braasch, L. G., McCabe, R. M., \& Daniel, K. (2016). Content integration across multiple documents reduces memory for sources. Reading and Writing.

Brand-Gruwel, S., \& Stadtler, M. (2011). Solving information-based problems: Evaluating sources and information. Learning and Instruction, 21, 175-179. doi:10.1016/j.learninstruc.2010.02.008.

Bråten, I., Britt, M. A., Strømsø, H. I., \& Rouet, J.-F. (2011a). The role of epistemic beliefs in the comprehension of multiple expository texts: Toward an integrated model. Educational Psychologist, 46, 48-70. doi:10.1080/00461520.2011.538647.

Bråten, I., Ferguson, L. E., Strømsø, H. I., \& Anmarkrud, Ø. (2014). Students working with multiple conflicting documents on a scientific issue: Relations between epistemic cognition while reading and sourcing and argumentation in essays. British Journal of Educational Psychology, 84, 58-85. doi:10.1111/bjep.12005.

Bråten, I., Stadtler, M., \& Salmerón, L. (2016a). The role of sourcing in discourse comprehension. In M. F. Schober, D. N. Rapp, \& M. A. Britt (Eds.), Handbook of discourse processes (2nd ed.). Routledge: London.

Bråten, I., Strøms $\varnothing$, H. I., \& Andreassen, R. (2016). Sourcing in professional education: Do text factors make any difference? Reading and Writing.

Bråten, I., Strømsø, H. I., \& Britt, M. A. (2009). Trust matters: Examining the role of source evaluation in students' construction of meaning within and across multiple texts. Reading Research Quarterly, 44, 6-28. doi:10.1598/RRQ.44.1.1.

Bråten, I., Strømsø, H. I., \& Salmerón, L. (2011b). Trust and mistrust when students read multiple information sources about climate change. Learning and Instruction, 21, 180-192. doi:10.1016/j. learninstruc.2010.02.002.

Britt, M. A., \& Aglinskas, C. (2002). Improving students' ability to identify and use source information. Cognition and Instruction, 20, 485-522. doi:10.1207/s1532690xci2004_2.

Britt, M. A., Perfetti, C. A., Sandak, R., \& Rouet, J. F. (1999). Content integration and source separation in learning from multiple texts. In S. R. Goldman, A. C. Graesser, \& P. van den Broek (Eds.), Narrative comprehension, causality, and coherence: Essays in honor of Tom Trabasso (pp. 209-233). Mahwah: Lawrence Erlbaum Associates.

Britt, M. A., \& Rouet, J.-F. (2012). Learning with multiple documents: Component skills and their acquisition. In J. R. Kirby \& M. J. Lawson (Eds.), Enhancing the quality of learning: Dispositions, instruction, and learning processes (pp. 276-314). New York: Cambridge University Press.

Bromme, R., \& Goldman, S. R. (2014). The public's bounded understanding of science. Educational Psychologist, 49, 59-69. doi:10.1080/00461520.2014.921572.

Bromme, R., Kienhues, D., \& Porsch, T. (2010). Who knows what and who can we believe? Epistemological beliefs are beliefs about knowledge (mostly) attained from others. In L. D. Bendixen \& F. C. Feucht (Eds.), Personal epistemology in the classroom: Theory, research, and implications for practice (pp. 163-193). Cambridge: Cambridge University Press. 
Bromme, R., Scharrer, L., Stadtler, M., Hömberg, J., \& Torspecken, R. (2015). Is it believable when it's scientific? How scientific discourse style influences laypeople's resolution of conflicts. Journal of Research in Science Teaching, 52, 36-57. doi:10.1002/tea.21172.

Casaló, L. V., Flavián, C., \& Guinalíu, M. (2011). Understanding the intention to follow the advice obtained in an online travel community. Computers in Human Behavior, 27, 622-633. doi:10.1016/j. chb.2010.04.013.

Chinn, C. A., \& Rinehart, R. W. (2016). Commentary: Advances in research on sourcing: Source credibility and reliable processes for producing knowledge claims. Reading and Writing.

Eysenbach, G., \& Köhler, C. (2002). How do consumers search for and appraise health information on the World Wide Web? Qualitative study using focus groups, usability tests, and in-depth interviews. British Medical Journal, 324, 573-577. doi:10.1136/bmj.324.7337.573.

Gerjets, P., Kammerer, Y., \& Werner, B. (2011). Measuring spontaneous and instructed evaluation processes during web search: Integrating concurrent thinking-aloud protocols and eye-tracking data. Learning and Instruction, 21, 220-231. doi:10.1016/j.learninstruc.2010.02.005.

Goldman, S. R., \& Scardamalia, M. (2013). Managing, understanding, applying, and creating knowledge in the information age: Next-generation challenges and opportunities. Cognition and Instruction, 31, 255-269. doi:10.1080/10824669.2013.773217.

Greenspan, S., Loughlin, G., \& Black, R. S. (2001). Credulity and gullibility in people with developmental disorders: A framework for future research. In L. M. Glidden (Ed.), International review of research in mental retardation (Vol. 24, pp. 101-135). New York: Academic Press.

Kammerer, Y., \& Gerjets, P. (2012). Effects of search interface and internet-specific epistemic beliefs on source evaluations during web search for medical information: An eye-tracking study. Behaviour and Information Technology, 31, 83-97. doi:10.1080/0144929X.2011.599040.

Kobayashi, K. (2014). Students' consideration of source information during the reading of multiple texts and its effect on intertextual conflict resolution. Instructional Science, 42, 183-205. doi:10.1007/ s11251-013-9276-3.

Lewandowski, D. (2011). The influence of commercial intent of search results on their perceived relevance. Proceedings of the 2011 iConference (iConference '11) (pp. 452-458). New York: ACM Press.

Metzger, M. J., \& Flanagin, A. J. (2013). Credibility and trust of information in online environments: The use of cognitive heuristics. Journal of Pragmatics, 59, 210-220. doi:10.1016/j.pragma.2013.07.012.

Perfetti, C. A., Rouet, J.-F., \& Britt, M. A. (1999). Toward a theory of documents representation. In H. V. Oostendorp \& S. R. Goldman (Eds.), The construction of mental representations during reading (pp. 99-122). Mahwah: Lawrence Erlbaum Associates.

Rouet, J.-F. (2006). The skills of document use: From text comprehension to web-based learning. Mahwah: Lawrence Erlbaum Associates.

Rouet, J.-F., Favart, M., Britt, M. A., \& Perfetti, C. A. (1997). Studying and using multiple documents in history: Effects of discipline expertise. Cognition and Instruction, 15, 85-106. doi:10.1207/ s1532690xci1501_3.

Rouet, J.-F., Le Bigot, L., de Pereyra, G., \& Britt, M. A. (2016). Whose story is this? Discrepancy triggers readers' attention to source information in short narratives. Reading and Writing.

Salmerón, L., Gómez, M., \& Fajardo, I. (2016). How students with intellectual disabilities evaluate recommendations from Internet forums. Reading and Writing.

Salmerón, L., Kammerer, Y., \& García-Carrión, P. (2013). Searching the Web for conflicting topics: Page and user factors. Computers in Human Behavior, 29, 2161-2171. doi:10.1016/j.chb.2013.04.034.

Salmerón, L., Macedo-Rouet, M., \& Rouet, J.-F. (2016). Multiple viewpoints increase students' attention to source features in social question and answer forum messages. Journal of the Association for Information Science and Technology,. doi:10.1002/asi.23585.

Sparks, J. R., \& Rapp, D. N. (2011). Readers' reliance on source credibility in the service of comprehension. Journal of Experimental Psychology. Learning, Memory, and Cognition, 37, 230-247. doi:10.1037/a0021331.

Stadtler, M., \& Bromme, R. (2007). Dealing with multiple documents on the WWW: The role of metacognition in the formation of documents models. International Journal of Computer Supported Collaborative Learning, 2, 191-210. doi:10.1007/s11412-007-9015-3.

Stadtler, M., \& Bromme, R. (2008). Effects of the metacognitive computer-tool met.a.ware on the web search laypersons. Computers in Human Behavior, 24, 716-737. doi:10.1016/j.chb.2007.01.023.

Stadtler, M., \& Bromme, R. (2014). The content-source integration model: A taxonomic description of how readers comprehend conflicting scientific information. In D. N. Rapp \& J. Braasch (Eds.), 
Processing inaccurate information: Theoretical and applied perspectives from cognitive science and the educational sciences (pp. 379-402). Cambridge: MIT Press.

Stadtler, M., Paul, J., Globoschütz, S., \& Bromme, R. (2015). Watch out!-An instruction raising students' epistemic vigilance augments their sourcing activities. In D. C. Noelle, R. Dale, A. S. Warlaumont, J. Yoshimi, T. Matlock, C. D. Jennings, \& P. P. Maglio (Eds.), Proceedings of the 37th annual conference of the cognitive science society (pp. 2278-2283). Austin: Cognitive Science Society.

Stadtler, M., Scharrer, L., Macedo-Rouet, M., Rouet, J.-F., \& Bromme, R. (2016). Improving vocational students' consideration of source information when deciding about science controversies. Reading and Writing.

Steffens, B., Britt, M. A., Braasch, J. L., Strøms $\varnothing$, H., \& Bråten, I. (2014). Memory for scientific arguments and their sources: Claim-evidence consistency matters. Discourse Processes, 51, 117-142. doi:10.1080/0163853X.2013.855868.

Strøms $\varnothing$, H. I., Bråten, I., \& Britt, M. A. (2010). Reading multiple texts about climate change: The relationship between memory for sources and text comprehension. Learning and Instruction, 20, 192-204. doi:10.1016/j.learninstruc.2009.02.001.

Strømsø, H. I., Bråten, I., \& Britt, M. A. (2011). Do students' beliefs about knowledge and knowing predict their judgement of texts' trustworthiness? Educational Psychology, 31, 177-206. doi:10. 1080/01443410.2010.538039.

Strømsø, H. I., Bråten, I., Britt, M. A., \& Ferguson, L. E. (2013). Spontaneous sourcing among students reading multiple documents. Cognition and Instruction, 31, 176-203. doi:10.1080/07370008.2013. 769994.

Thomm, E., \& Bromme, R. (2016). How source information shapes lay interpretations of science conflicts: Interplay between sourcing, conflict explanation, source evaluation, and claim evaluation. Reading and Writing.

Thomm, E., Hentschke, J., \& Bromme, R. (2015). The explaining conflicting scientific claims (ECSC) questionnaire: Measuring laypersons' explanations for conflicts in science. Learning and Individual Differences, 37, 139-152. doi:10.1016/j.lindif.2014.12.001.

Von der Mühlen, S., Richter, T., Schmid, S., Schmidt, E. M., \& Berthold, K. (2016). The use of sourcerelated strategies in evaluating multiple psychology texts: A student-scientist comparison. Reading and Writing.

Wiley, J., Goldman, S. R., Graesser, A. C., Sanchez, C. A., Ash, I. K., \& Hemmerich, J. A. (2009). Source evaluation, comprehension, and learning in internet science inquiry tasks. American Educational Research Journal, 46, 1060-1106. doi:10.3102/0002831209333183.

Wineburg, S. S. (1991). Historical problem solving: A study of the cognitive processes used in the evaluation of documentary and pictorial evidence. Journal of Educational Psychology, 83, 73-87. doi:10.1037//0022-0663.83.1.73. 